\title{
FT/TFL1: Calibrating Plant Architecture
}

\author{
Tatiana Souza Moraes ${ }^{1}$, Marcelo Carnier Dornelas ${ }^{2}$ and Adriana Pinheiro Martinelli* \\ 'Laboratório de Biotecnologia Vegetal, Centro de Energia Nuclear na Agricultura, Universidade de São Paulo, \\ Piracicaba, Brazil, ${ }^{2}$ Departamento de Biologia Vegetal, Instituto de Biologia, Universidade Estadual de Campinas, \\ Campinas, Brazil
}

There is a very large diversity in plant architecture in nature. Over the past few years, novel theoretical concepts and analytical methods have emerged as powerful tools to understand important aspects of plant architecture. Plant architecture depends on the relative arrangement of three types of organs: leaves, shoots, and flowers. During plant development, the architecture is modulated by the balance of two homologous proteins: FLOWERING LOCUS T (FT) and TERMINAL FLOWER 1 (TFL1). The FT/TFL1 balance defines the plant growth habit as indeterminate or determinate by modulating the pattern of formation of vegetative and reproductive structures in the apical and axillary meristems.

OPEN ACCESS

Edited by:

Cristina Ferrandiz, Instituto de Biología Molecular y Celular de Plantas (IBMCP),

Spain

Reviewed by: Joseph Colasanti, University of Guelph, Canada

Gerhard Buck-Sorlin, Agrocampus Ouest, France

*Correspondence: Adriana Pinheiro Martinelli adriana.martinelli@usp.br

Specialty section:

This article was submitted to Plant Development and EvoDevo, a section of the journal Frontiers in Plant Science

Received: 25 October 2018 Accepted: 21 January 2019 Published: 13 February 2019

Citation: Moraes TS, Dornelas MC and Martinelli AP (2019) FT/TFL1: Calibrating Plant Architecture.

Front. Plant Sci. 10:97. doi: 10.3389/fpls.2019.00097
Here, we present a summarized review of plant architecture and primarily focus on the FT/TFL 1 balance and its effect on plant form and development. We also propose passion fruit as a suitable model plant to study the effect of FT/TFL 1 genes on plant architecture.

Keywords: FT/TFL1, model plant, Passiflora, plant architecture, tendril

\section{INTRODUCTION}

Our understanding of plant architecture has advanced in the last few decades, and research in this field has given rise to innovations in various aspects of plant science. The use of high-performance computers for plant growth data analysis and simulation has contributed to the development of various interpretations of plant architecture (Kuchen et al., 2012; Coen et al., 2017; Whitewoods and Coen, 2017).

Plant architecture is determined by the number and arrangement of organs that are formed from the shoot apical meristem (SAM) (Benlloch et al., 2007). During the vegetative stage, the SAM gives rise to shoots and leaves, and after transition to the reproductive stage it produces flowers (Benlloch et al., 2007).

In the annual model plant Arabidopsis thaliana, the growth habit is monopodial and the apical meristem remains indeterminate and active throughout the entire plant life cycle (Bowman, 1994). The resulting stem bears lateral branches, leaves, and flowers, and there is a clear distinction between the vegetative and reproductive stages (Bradley et al., 1997).

Perennial plants differ from annual herbaceous plants, such as Arabidopsis, in a range of characteristics that influence their growth pattern and consequently the plant architecture. The branching habit of a perennial plant is more complex because an axillary meristem can have multiple fates-it either directly forms a shoot, or differentiates into a floral bud that opens the following spring after a dormant period, or remains dormant indefinitely. In addition, in perennial plants, the SAM preserves a high level of vegetative identity or "vegetativeness" 
(Prusinkiewicz et al., 2007). According to these authors, the meristem will form either a flower or a branch depending on its "vegetativeness"; high "vegetativeness" corresponds to an indeterminate shoot growth, and low levels of "vegetativeness" lead to determinate growth and development of floral meristem (Prusinkiewicz et al., 2007).

Plant architecture is controlled by genetic mechanisms associated with environmental factors and largely dependent on meristem identity, which establishes the development of shoots or flowers. Extensive studies on genetic mechanisms controlling meristem identity in Arabidopsis have revealed that plant architecture is regulated by a few groups of genes (Bradley et al., 1997; Conti and Bradley, 2007; Ho and Weigel, 2014). Among those, we can highlight FLOWERING LOCUS T (FT) and TERMINAL FLOWER 1 (TFL1), both belonging to the FT/TFL1 gene family and encoding proteins similar to phosphatidylethanolamine binding proteins (PEBP) (Wickland and Hanzawa, 2015). The balance between these two homologous proteins, FT and TFL1, controls the indeterminate and determinate growth in plants and modulates plant architecture, regulating the formation pattern of vegetative and reproductive organs from the apical meristem (Park et al., 2014).

In the present paper, we report an updated view on the modulation of axillary meristems and plant architecture, with a primary focus on the role of FT/TFL1 genes. We introduce new discussions about the current knowledge in this field and the possible implications and perspectives concerning plant architecture in plant developmental studies.

\section{EFFECTS OF FT/TFL1 BALANCE IN ANNUAL PLANTS: ARABIDOPSIS}

In Arabidopsis, six genes have been identified in the FT/TFL1 family: FLOWERING LOCUS T (FT) and TWIN SISTER OF FT (TSF), involved in flowering promotion and belonging to the FT-like subfamily; TERMINAL FLOWER 1 (TFL1), BROTHER OF FT AND TFL1 (BFT) and Arabidopsis thaliana CENTRORADIALIS HOMOLOG (ATC), involved in flowering repression and belonging to the subfamily TFL1-like; and MOTHER OF FT AND TFL1 (MFT), belonging to the MFT-like subfamily and involved in the regulation of seed germination (Kobayashi et al., 1999; Xi et al., 2010; Wickland and Hanzawa, 2015).

FT and TFL1 have antagonistic functions in plant development. Considered as the florigen agent, FT activates the flowering pathway, whereas TFL1 represses flowering and is responsible for the maintenance of the inflorescence meristem. The FT/ TFL1 balance modulates the plant architecture because both proteins are involved in the control of the indeterminate versus determinate plant growth habit, which is essentially based on the production pattern of vegetative versus reproductive organs by the apical meristem (Matsoukas et al., 2012; Xu et al., 2012; Jaeger et al., 2013; Nakano et al., 2015; Patil et al., 2017).

In Arabidopsis, the transcription factor CONSTANS (CO) activates FT in the leaves, where the gene is transcribed and translated, and its protein is then transported via phloem into the vegetative apex. In the apex, the FT protein forms a complex with a bZIP protein, FLOWERING LOCUS D (FD). This complex activates genes involved in floral meristem identity, such as $L F Y$ and APETALA1, thereby inducing flowering (Abe et al., 2005). The $f t$ mutants flower late and present indeterminate growth, whereas the overexpression of FT causes early flowering and conversion of the SAM into a terminal flower (Corbesier et al., 2007). In contrast, the expression of TFL1 in the SAM maintains the indeterminate growth and represses the floral meristem identity genes. The TFL1 protein is also capable of interacting with the FD transcription factor. Thus, $t f l 1$ mutants flower early and their SAM is converted into a terminal flower. In contrast, overexpression of TFL1 causes late flowering and prevents the formation of a terminal flower (Bradley et al., 1997).

\section{EFFECTS OF FT/TFL1 BALANCE IN PERENNIALS: TOMATO}

In tomato (Solanum lycopersicum) the balance between FT and TFL1 orthologs SINGLE FLOWER TRUSS (SFT) and SELFPRUNING $(S P)$, respectively, coordinate the primary growth with regular sympodial cycles. A high SFT/SP ratio in the meristem promotes determinate growth, eventually converting the SAM into a flower, while a low SFT/SP balance promotes indeterminate plant growth (Pnueli et al., 1998, 2001; Lifschitz et al., 2014).

Studies have shown that sft mutations may increase the productivity of tomato plants through a determinate growth habit (Park et al., 2014). In sft, the loss of florigen activity results in a highly vegetative plant with fewer flowers and fruits. When plants with a determinate growth are heterozygous for SFT, there is a partial reduction of florigen activity and a slight suppression of SP, resulting in more sympodial branches and inflorescences. In contrast, when $S P$ is present as a dominant allele, plants show indeterminate growth and continuous formation of inflorescences and fruits. Nonetheless, when the tomato plant has a recessive allele for this gene, it exhibits a specific architecture characterized by an early interruption of inflorescence production and shorter plant stature (Pnueli et al., 1998, 2001; Jiang et al., 2013). These results suggest that sft and $s p$ mutations combined with heterozygous dosage effects should be further explored to modulate flowering and plant architecture and optimize tomato yields.

\section{HOW FT/TFL1 GENE DUPLICATION CONTRIBUTES TO THE EVOLUTION OF PLANT ARCHITECTURE}

Gene duplication, a process that gives rise to paralogs, is a very common phenomenon in plants and an important source of new adaptive functions prone to selection during evolution (Kondrashov et al., 2002). Some gene pairs formed by duplication might have a short lifetime-only one copy might be kept functional, while the other copy is pseudogenized-but other gene pairs might persist after duplication. Paralog proteins may 
give rise to new functions through mutations that affect, for example, gene expression or amino acid sequences, resulting in different phenotypes that arise through adaptive evolution of new protein functions (Lynch and Conery, 2000).

Apparently, during evolution, some FT homologous genes acquired the function of flowering suppression. In some species, there is an FT with a repression function that antagonizes the flowering induction function of its paralog (Kotoda et al., 2010; Pin et al., 2010; Hsu et al., 2011; Harig et al., 2012). It is of great significance that the evolution of FT paralogs might represent a common strategy in plants to refine floral initiation according to multiple environmental and endogenous pathways intrinsic to each individual.

In Beta vulgaris, the regulation of flowering time is controlled by BvFT1 and BvFT2, which show high sequence similarity to the Arabidopsis FT protein (AtFT). These genes regulate flowering time in response to low temperatures during winter associated with the phenomenon of vernalization. However, these two paralog genes in beet have antagonistic functions. While BvFT2, which is functionally conserved, is essential for flowering (it is expressed late in the afternoon, in long days), BvFT1 represses the flowering (it is preferentially expressed early in the morning, in short days) (Pin et al., 2010). Pin et al. (2010) observed that both proteins, BvFT1 and BvFT2, contain amino acids that determine the FT function (Tyr85 and Gln140). However, the binding of specific residues at the external loop of their tertiary structures differed between the two proteins. Thus, these authors suggest that BvFT1 was initially a promoter of flowering, but that mutations within the outer loop of the protein resulted in a change in function toward flowering repression.

Similarly, two FT homolog proteins in Populus trichocarpa are required to coordinate the recurrent seasonal flowering cycle in response to temperature (Hsu et al., 2011). PtFT2 is involved in the vegetative growth, and it is activated by high temperatures and long photoperiods during spring and summer. In contrast, PtFT1, which activates reproductive growth, is repressed by high temperatures and induced by winter low temperatures.

Similarly, three out of the four FT homologs identified in Nicotiana tabacum repress flowering. Harig et al. (2012) found that all four genes were expressed in leaves under short-day conditions, and at least NtFT3 expression was restricted to the phloem companion cells. NtFT1, NtFT2, and NtFT3 proteins are floral inhibitors, whereas only NtFT4 is a floral inducer (Harig et al., 2012).

Although TFL1 gene duplications have also been described in the literature (Carmona et al., 2007; Li et al., 2015), the specific function of each paralog remains unclear, with no reports on TFL1 paralogs possessing an antagonistic function such as the activation of flowering (Carmona et al., 2007; Li et al., 2015).

\section{MODULATION AND COMPLEXITY OF AXILLARY MERISTEMS}

The axillary meristems (AMs) are important elements in establishing plant architecture and their reproductive success (Wang and Jiao,
2018). The flexibility of the AM activity is directly related to the FT/TFL1 balance (McGarry and Ayre, 2012).

In summary, a plant with a high FT/TFL1 ratio flowers early and presents a short stature as its apical meristem is converted into a terminal flower. As this ratio decreases, the level of vegetative identity, or "vegetativeness," increases and the plants produce fewer flowers. Consequently, the repression of FT considerably increases vegetative growth (Figure 1).

In most annual plants, the SAM remains indeterminate, while the axillary meristems are determinate. Thus, the SAM gives rise to a vegetative meristem, when FT/TFL1 ratio is low. As the plant ages, FT transport increases because there are more leaves contributing to the FT pool and, in the apex, the effects of accumulated FT exceed the TFL1 function. As a result, a transition from a vegetative to a reproductive meristem is observed and, subsequently, the plant life cycle is completed. In contrast, perennial plants present high levels of TFL1 in the SAM, which remains vegetative, while in the axillary meristems, the FT level prevails, activating genes involved in floral meristem identity (McGarry and Ayre, 2012).

In Arabidopsis, the protein encoded by the gene BRANCHED1 $(B R C 1)$ interacts with FT, modulating its activity in the axillary buds to repress the premature floral transition of axillary meristems (Hiraoka et al., 2013; Niwa et al., 2013). BRC1, also known as TCP18, is a member of the TCP family, a plant-specific family of transcription factors involved in a large variety of developmental processes, such as cell proliferation and growth, mainly in meristems and lateral organs. Through these processes, it is involved in the establishment of plant form and architecture (Aggarwal et al., 2010; Manassero et al., 2013).

In perennial plants such as lianas, woody climbing vines that are abundant in tropical forests, the growth habit differs. The acquisition of the climbing habit constitutes an innovation, and its success in climbers is related to the development of specialized structures such as tendrils. Lianas begin their life on the floor, but their survival depends on trees for support as they climb upward and compete for sunlight. Thus, their SAM is characterized by indeterminate vegetative growth and repressed development of the AMs, facilitating the lianas to reach the forest canopy (Rodriguez-Ronderos et al., 2016; Sousa-Baena et al., 2018).

The Arabidopsis AMs are simple in comparison to AMs in other families such as Vitaceae and Passifloraceae. Additional accessory meristems, which give rise to tendrils or inflorescences, are a special feature of Vitaceae. In grapevine (Vitis spp.), a genus of woody perennial vines, adult plants have specific AMs called uncommitted lateral meristems. These meristems are located opposite to the leaves in the expanded shoot and give rise to tendrils for an extended period before the plant initiates flowering. However, upon flowering induction, the inflorescences are formed in place of tendrils from the same uncommitted lateral meristems (May, 2004; Carmona et al., 2008).

In Passiflora species, AMs acquire different features during life stages. Taking passion fruit ( $P$. edulis) as an example, the AMs of juvenile plants give rise to a vegetative meristem, those in adult vegetative plants produce a tendril next to a 


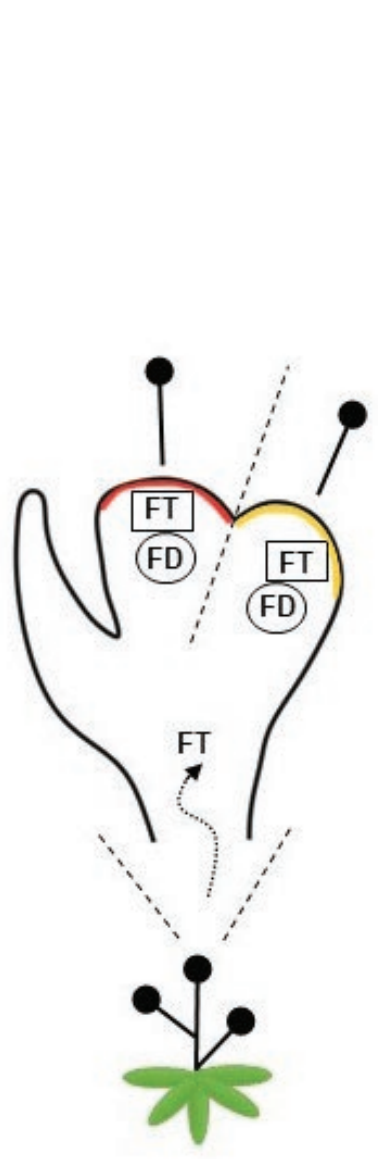

A

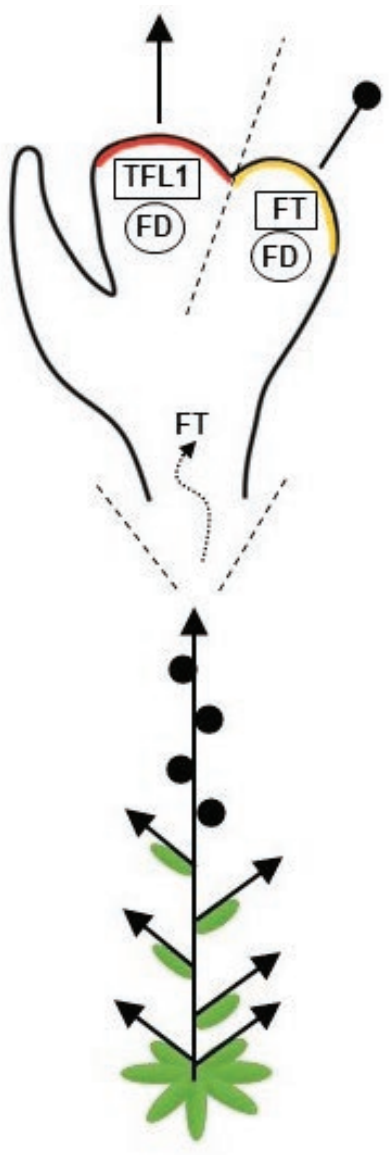

B

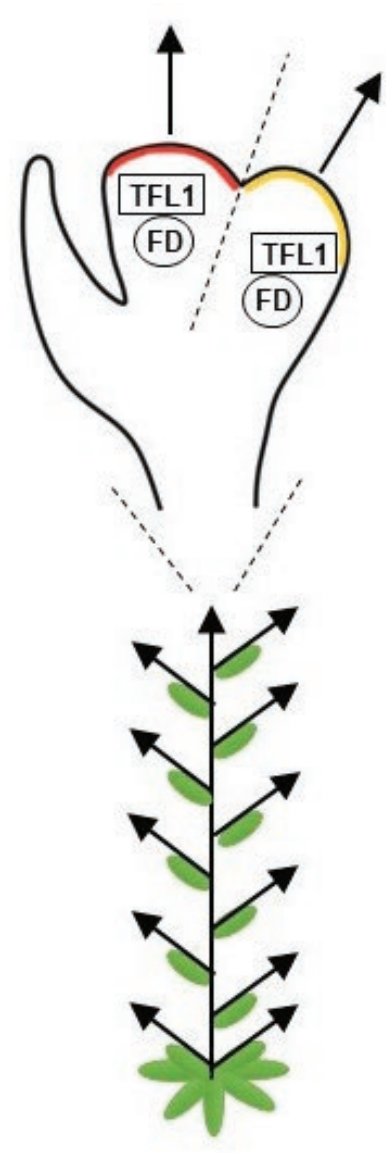

C

FIGURE 1 | Representation of the changes in plant architecture attributable to the balance between FLOWERING LOCUS T (FT) and TERMINAL FLOWER (TFL1). FT and TFL1 compete for FLOWERING LOCUS D (FD) binding. (A) A high FT/TFL1 ratio causes early flowering in plants with short stature, since its apical and axillary meristems are converted into flowers. (B) A moderate ratio of FT/TFL1 allows for a balanced development between the shoots and flowers along the plant axes. (C) A low FT/TFL1 ratio increases the plant vegetative growth and the apical and axillary meristems give rise to shoots. A red region represents the shoot apical meristem, an orange region represents the axillary meristem, arrows represent indeterminate meristems, and black circles represent flowers.

vegetative meristem, and finally, adult reproductive plants form, in addition to the vegetative meristem, an AM that divides into two primordia to form tendrils and flowers simultaneously (Ulmer and Macdougal, 2004; Dornelas et al., 2006; Cutri et al., 2013). Passion fruit species evolved in ecosystems in which competition for light is the norm, due to dense vegetation (Ulmer and Macdougal, 2004). Therefore it can be considered an adaptive advantage the ability to climb on other plants in order to reach the top of the canopy. Passiflora species endure a very short juvenile stage (about eight plastochrons) under the canopy shadows and after transitioning to the adult stage, tendrils are produced by lateral axillary meristems (Cutri et al., 2013). The production of flowers is repressed in P. edulis plants under shaded conditions, and thus tendrils allow the plant to climb to the top of the canopy where flowers can develop. According to these observations, flowers are formed only after tendrils are formed and they share a common ontogenetic origin (Cutri et al., 2013; Sousa-Baena et al., 2018). The number and position of flowers formed from the axillary meristems diverge among Passiflora species. Cutri et al. (2013) showed by comparing different Passiflora species under distinct environmental conditions that a great ontogenetic plasticity exists that is normally restrained by genetic, hormonal and environmental constraints. Therefore we postulate that what appears to be a species-specific program regulating the fate of the Passiflora lateral axillary meristems, is in great part due to a balance of the expression patterns of FT/TFL1 orthologs in passion fruits.

\section{CONCLUSION}

The balance between FT/TFL1 ortholog genes is important for adaptation of plants to diverse environmental conditions. It is notable that domestication of several wild and exotic species into agronomic cultures with specific growth habits results from 
a selection of the differential balance between FT/TFL1. Thus, studies characterizing the interaction between these genes become an important tool for breeding programs of plants of commercial interest, since the ability to modulate plant size might allow increasing planting density, facilitate fruit harvest, and increase crop productivity, among other agronomic benefits. Considering that passion fruit AMs are predicted to be more complex in comparison with AMs in other species, we propose passion fruit as an appropriate model to study the FT/TFL1 balance in order to understand how AM modulation gives rise to different structures.

\section{DATA AVAILABILITY}

The datasets generated for this study are available on request to the corresponding author.

\section{REFERENCES}

Abe, M., Kobayashi, Y., Yamamoto, S., Daimon, Y., Yamaguchi, A., Ikeda, Y., et al. (2005). FD, a bZIP protein mediating signals from the floral pathway integrator FT at the shoot apex. Science 309, 1052-1056. doi: 10.1126/ science. 1115983

Aggarwal, P., Das Gupta, M., Joseph, A. P., Chatterjee, N., Srinivasan, N., and Nath, U. (2010). Identification of specific DNA binding residues in the TCP family of transcription factors in Arabidopsis. Plant Cell 22, 1174-1189. doi: 10.1105/tpc.109.066647

Benlloch, R., Berbel, A., Serrano-Mislata, A., and Madueño, F. (2007). Floral initiation and inflorescence architecture: a comparative view. Ann. Bot. 100, 659-676. doi: 10.1093/aob/mcm 146

Bowman, J. (Ed.) (1994). Arabidopsis: an Atlas of morphology and development. New York: Springer-Verlag.

Bradley, D., Ratcliffe, O., Vincent, C., Carpenter, R., and Coen, E. (1997). Inflorescence commitment and architecture in Arabidopsis. Science 275, 80-83. doi: 10.1126/science.275.5296.80

Carmona, M. J., Calonje, M., and Martínez-Zapater, J. M. (2007). The FT/ TFL1 gene family in grapevine. Plant Mol. Biol. 63, 637-650. doi: 10.1007/ s11103-006-9113-z

Carmona, M. J., Chaib, J., Martınez-Zapater, J. M., and Thomas, M. R. (2008). A molecular genetic perspective of reproductive development in grapevine. J. Exp. Bot. 59, 2579-2596. doi: 10.1093/jxb/ern 160

Coen, E., Kennaway, R., and Whitewoods, C. (2017). On genes and form. Development 144, 4203-4213. doi: 10.1242/dev.151910

Conti, L., and Bradley, D. (2007). TERMINAL FLOWER1 is a mobile signal controlling Arabidopsis architecture. Plant Cell 19, 767-778. doi: 10.1105/ tpc.106.049767

Corbesier, L., Vincent, C., Jang, S., Fornara, F., Fan, Q., Searle, I., et al. (2007). FT protein movement contributes to long-distance signaling in floral induction of Arabidopsis. Science 316, 1030-1033. doi: 10.1126/science.1141752

Cutri, L., Nave, N., Ami, M. B., Chayut, N., Samach, A., and Dornelas, M. C. (2013). Evolutionary, genetic, environmental and hormonal-induced plasticity in the fate of organs arising from axillary meristems in Passiflora spp. Mech. Dev. 130, 61-69. doi: 10.1016/j.mod.2012.05.006

Dornelas, M. C., Fonseca, T. C., and Rodriguez, A. P. M. (2006). "Brazilian passion flowers and novel passionate tropical flowering gems" in Floriculture, ornamental and plant biotechnology. ed. Silva, J. A. T. (London: Global Science Books), 629-639.

Harig, L., Beinecke, F. A., Oltmanns, J., Muth, J., Müller, O., Rüping, B., et al. (2012). Proteins from the FLOWERING LOCUS T-like subclade of the PEBP family act antagonistically to regulate floral initiation in tobacco. Plant J. 72, 908-921. doi: 10.1111/j.1365-313X.2012.05125.x

\section{AUTHOR CONTRIBUTIONS}

TM and MD designed the initial manuscript. TM wrote the initial draft of the manuscript and conceived the figure. TM, $\mathrm{MD}$, and $\mathrm{AM}$ contributed reviewing and discussing the manuscript to produce its final version.

\section{FUNDING}

The authors acknowledge financial support from Coordenação de Aperfeiçoamento de Pessoal de Nível Superior (CAPES, Brazil, finance code 001), Conselho Nacional de Desenvolvimento Cientifico e Tecnológico (CNPq, Brazil, fellowship grant 305386/2015-8), and Fundação de Amparo à Pesquisa do Estado de São Paulo (FAPESP, São Paulo, Brazil, grant 2015/18900-3, scholarship grant 2015/25633-1).

Hiraoka, K., Yamaguchi, A., Abe, M., and Araki, T. (2013). The florigen genes FT and TSF modulate lateral shoot outgrowth in Arabidopsis thaliana. Plant Cell Physiol. 54, 352-368. doi: 10.1093/pcp/pcs168

Ho, W. W., and Weigel, D. (2014). Structural features determining flower promoting activity of Arabidopsis FLOWERING LOCUS T. Plant Cell 26, 552-564. doi: 10.1105/tpc.113.115220

Hsu, C. Y., Adams, J. P., Kim, H., No, K., Ma, C., Strauss, S. H., et al. (2011). FLOWERING LOCUS $\mathrm{T}$ duplication coordinates reproductive and vegetative growth in perennial poplar. Proc. Natl. Acad. Sci. USA 108, 10756-10761. doi: $10.1073 /$ pnas. 1104713108

Jaeger, K. E., Pullen, N., Lamzin, S., Morris, R. J., and Wigge, P. A. (2013). Interlocking feedback loops govern the dynamic behavior of the floral transition in Arabidopsis. Plant Cell 25, 820-833. doi: 10.1105/tpc.113.109355

Jiang, K., Liberatore, K. L., Park, S. J., Alvarez, J. P., and Lippman, Z. B. (2013). Tomato yield heterosis is triggered by a dosage sensitivity of the florigen pathway that fine-tunes shoot architecture. PLoS Genet. 9:e1004043. doi: 10.1371/journal.pgen.1004043

Kobayashi, Y., Kaya, H., Goto, K., Iwabuchi, M., and Araki, T. (1999). A pair of related genes with antagonistic roles inmediating flowering signals. Science 286:1960. doi: 10.1126/science.286.5446.1960

Kondrashov, F. A., Rogozin, I. B., Wolf, Y. I., and Koonin, E. V. (2002). Selection in the evolution of gene duplications. Genome Biol. 3, 1-9. doi: 10.1186/ gb-2002-3-2-research0008

Kotoda, N., Hayashi, H., Suzuki, M., Igarashi, M., Hatsuyama, Y., and Kidou, S. (2010). Molecular characterization of FLOWERING LOCUS T-like genes of apple (Malus domestica Borkh.). Plant Cell Physiol. 51, 561-575. doi: 10.1093/ pcp/pcq021

Kuchen, E. E., Fox, S., Reuille, P. B., Kennaway, R., Bensmihen, S., Avonto, J., et al. (2012). Generation of leaf shape through early patterns of growth and tissue polarity. Science 335:1092. doi: 10.1126/science.1214678

Li, C., Luo, L., Fu, Q., Niu, L., and Xu, Z. F. (2015). Identification and characterization of the FT/TFL1 gene family in the biofuel plant Jatropha curcas. Plant Mol. Biol. Rep. 33, 326-333. doi: 10.1007/s11105-014-0747-8

Lifschitz, E., Ayre, B. G., and Eshed, Y. (2014). Florigen and anti-florigen: systemic mechanism for coordinating growth and termination in flowering plants. Front. Plant Sci. 5:465. doi: 10.3389/fpls.2014.00465

Lynch, M., and Conery, J. S. (2000). The evolutionary fate and consequences of duplicate genes. Science 10, 1151-1155. doi: 10.1126/science.290.5494.1151

Manassero, N. G., Viola, I. L., Welchen, E., and Gonzalez, D. H. (2013). TCP transcription factors: architectures of plant form. BioMol Concepts 4, 111-127. doi: 10.1515/bmc-2012-0051

Matsoukas, I. G., Massiah, A. J., and Thomas, B. (2012). Florigenic and antiflorigenic signaling in plants. Plant Cell Physiol. 53, 1827-1842. doi: $10.1093 / \mathrm{pcp} / \mathrm{pcs} 130$ 
May, P. (2004). Flowering and fruitset in grapevines. Adelaide: Lythrum Press. McGarry, R. C., and Ayre, B. G. (2012). Manipulation plant architecture with members of the CETS gene family. Plant Sci. 188-189, 71-81. doi: 10.1016/j. plantsci.2012.03.002

Nakano, Y., Higuchi, Y., Yoshida, Y., and Hisamatsu, T. (2015). Environmental responses of the FT/TFL1 gene family and their involvement in flower induction in Fragaria $\times$ ananassa. J. Plant Physiol. 177, 60-66. doi: 10.1016/j. jplph.2015.01.007

Niwa, M., Daimon, Y., Kurotani, K., Higo, A., Pruneda-Paz, J., Breton, G., et al. (2013). BRANCHED1 interacts with FLOWERING LOCUS T to repress the floral transition of the axillary meristems in Arabidopsis. Plant Cell 25, 1228-1242. doi: 10.1105/tpc.112.109090

Park, S. J., Jiang, K., Tal, L., Yichie, Y., Gar, O., Zamir, D., et al. (2014). Optimization of crop productivity in tomato using induced mutation in the florigen pathway. Nat. Genet. 46, 1337-1342. doi: 10.1038/ng.3131

Patil, H. B., Chaurasia, A. K., Azeez, A., Krishna, B., Subramaniam, V. R., Sane, A. P., et al. (2017). Characterization of two TERMINAL FLOWER1 homologs PgTFL1 and PgCENa from pomegranate (Punica granatum L.). Tree Physiol. 38, 772-784. doi: 10.1093/treephys/tpx154

Pin, P. A., Benlloch, R., Bonnet, D., Wremerth-Weich, E., Kraft, T., and Gielen, J. J. (2010). An antagonistic pair of FT homologs mediates the control of flowering time in sugar beet. Science 330, 1397-1400. doi: 10.1126/science.1197004

Pnueli, L., Carmel-Goren, L., Hareven, D., Gutfinger, T., Alvarez, J., and Ganal, M. (1998). The SELF-PRUNING gene of tomato regulates vegetative to reproductive switching of sympodial meristems and is the ortholog of CEN and TFL1. Development 125, 1979-1989.

Pnueli, L., Gutfinger, T., Hareven, D., Ben-Naim, O., Ron, N., and Adir, N. (2001). Tomato SP-interacting proteins define a conserved signaling system that regulates shoot architecture and flowering. Plant Cell 13, 2687-2702. doi: 10.1105/tpc.13.12.2687

Prusinkiewicz, P., Erasmus, Y., Lane, B., Harder, A. D., and Coen, E. (2007). Evolution and development of inflorescence architectures. Science 316, 1452-1455. doi: 10.1126/science.1140429
Rodriguez-Ronderos, M. E., Bohrer, G., Sanchez-Azofeifa, A., Powers, J., and Schnitzer, S. A. (2016). Contribution of lianas to plant area index and canopy structure in a Panamanian forest. Ecology 97, 3271-3277. doi: 10.1002/ecy.1597

Sousa-Baena, M. S., Sinha, N. R., Hernandes-Lopes, J., and Lohmann, L. G. (2018). Convergent evolution and the diverse ontogenetic origins of tendrils in Angiosperms. Front. Plant Sci. 9:a.403. doi: 10.3389/fpls.2018.00403

Ulmer, T., and Macdougal, J. M. (2004). Passiflora: passionflowers of the world. Portland Oregon: Timber Press.

Wang, Y., and Jiao, Y. (2018). Axillary meristem initiation: a way to branch out. Curr. Opin. Plant Biol. 41, 61-66. doi: 10.1016/j.pbi.2017.09.001

Wickland, D. P., and Hanzawa, Y. (2015). The FLOWERING LOCUS T/TERMINAL FLOWER 1 gene family: functional evolution and molecular mechanisms. Mol. Plant 8, 983-997. doi: 10.1016/j.molp.2015.01.007

Whitewoods, C. D., and Coen, E. (2017). Growth and development of threedimensional plant form. Curr. Biol. 27, R910-R918. doi: 10.1016/j. cub.2017.05.079

Xi, W., Liu, C., Hou, X., and Yu, H. (2010). MOTHER OF FT AND TFL1 regulates seed germination through a negative feedback loop modulating ABA signaling in Arabidopsis. Plant Cell 22, 1733-1748. doi: 10.1105/tpc.109.073072

Xu, F., Ron, X., Huang, X., and Cheng, S. (2012). Recent advances of FLOWERING LOCUS T gene in higher plants. Int. J. Mol. Sci. 13, 3773-3781. doi: 10.3390/ ijms 13033773

Conflict of Interest Statement: The authors declare that the research was conducted in the absence of any commercial or financial relationships that could be construed as a potential conflict of interest.

Copyright (c) 2019 Moraes, Dornelas and Martinelli. This is an open-access article distributed under the terms of the Creative Commons Attribution License (CC BY). The use, distribution or reproduction in other forums is permitted, provided the original author(s) and the copyright owner(s) are credited and that the original publication in this journal is cited, in accordance with accepted academic practice. No use, distribution or reproduction is permitted which does not comply with these terms. 